\title{
Sliding mode approach to torque and pitch control for an wind energy system using FPGA
}

\author{
BIDYADHAR SUBUDHI and PEDDA SURESH OGETI
}

\begin{abstract}
Wind energy, being a fluctuating resource, requires a tight control management to ensure stability when integrated with the grid system. This has triggered interest towards developing advanced controllers. Hence this paper presents the study of a variable speed wind energy conversion system that uses a Double Fed Induction Generator (DFIG). Above rated wind speed, pitch control has been applied and below the rated speed torque control has been adopted. Generator torque control is able to reduce the effects of the pitch actuator limitations. Sliding mode control is applied for torque and pitch control in WECS and it has been implemented in MATLAB SIMULINK and FPGA to achieve control of active and reactive power exchange between the stator of the DFIG and the grid. Performance parameters like pitch angle, active, reactive power, turbine speed, and DC voltage has been compared by using SMC, Hill Climbing (HC) Algorithm and Perturb and Observe $(\mathrm{P} \& \mathrm{O})$ Algorithm and performance for these three methods has been simulated and implemented in FPGA. Total Harmonic Distortion for all the performance parameters has been reported. Hardware implementation of developed algorithm was accomplished with the help of Xilinx system generator and Xilinx Tool Kit.
\end{abstract}

Key words: wind-energy conversion systems (WECSs), sliding mode control (SMC), torque, pitch control, hill climbing (HC), perturb and observe (P\&O), FPGA

\section{Introduction}

Compared to all renewable energies, wind energy is facing the fastest development. As a consequence a lot of research is developed in this field. The WECS consists of a variable speed wind turbine model coupled to a wind generator. The varying aerodynamic torque and pitch Control of the wind turbine are incorporated in the simulation with the use of a MATLAB/SIMULINK and FPGA tools in order to obtain the characteristics of wind as desired. Wind generator connected to wind turbine shaft gives variable voltage which is further rectified and placed at the input terminal of voltage source converter.

Harnessing wind energy for electric power generation is an area of research interest and nowadays the emphasis is on the cost-effective utilization of this energy aiming at

The Authors are with Department of Electrical Engineering, National Institute of Technology, Rourkela-769008, Odisha, India. Email: bidyadharnitrkl@gmail.com

Received 28.06.2012. 
quality and reliability in the electricity delivery [1]. A gain scheduling controller for pitch Control in wind turbine was proposed in [2]-[4], which changes controller gains with the changes of wind speed or other parameters. This means that accurate wind speed should be available to the controller. But the wind speed is usually measured on the tower and does not represent the wind speed at the turbine plant, which makes the practical implementation of gain scheduling very difficult [5].

When the wind speed is over rating, the objective of controlling the wind power system is to maintain the constant output power. At present, the sliding mode variable structure controlling has been used in wind power control system [6]. As a matter of fact, it is linear controlling, shares common shortcomings with the same kind of controllers.

Enhanced performance and controllability of a 2-MW WECS [7] through pitch control for speed regulation where the focus has been to design a controller with disturbance attenuation. The drawback in this method is considering the external disturbance that represents the driving signals generating the disturbances, instead of considering the actual disturbances in WECSs.

The variable pitch controlling can be achieved by exact linearization of first-order wind power system based on differential geometry method [8]. This is nonlinear controlling, but the model is too simple and not being able to represent the accurate dynamics.

\section{Problem statement}

The controller gains have to be adjusted continuously, since the wind speed is continuously changing and the dynamics of wind are complex. So the controllers have to be designed with the components which are compatible with the fast variations in the speed and which can solve the complex dynamic manipulations very easily. This has motivated to select the FPGA which performs the calculations faster and reprograms the entire changes in wind speed for obtaining the better value within less span of time.

The objective of this work is to develop controllers for the generator torque and the pitch angle of the wind power system based on DFIG using SMC. For above rated speed, pitch control is adopted and for low speeds, the torque control has been used for controlling by considering the actual values of pitch and torque which are adjusted continuously according to the variations in wind speed in WECSs by SMC. Wind Turbine Modeling and FPGA implementation flow are presented in sec. 2, control design is presented in sec. 3 and the results are presented and discussed in sec. 4.

Fig. 1 shows the general block diagram of WECS. The power generated from the DFIG is controlled by PWM controls in boost converter and in inverter connected on grid side. For obtaining MPPT, two controls have been proposed using SMC, namely pitch and Torque control and have been elaborated in sec. 3. Finally these two controls are implemented in FPGA and compared the results with Hill Climbing algorithm and Perturb and Observe Algorithm. 


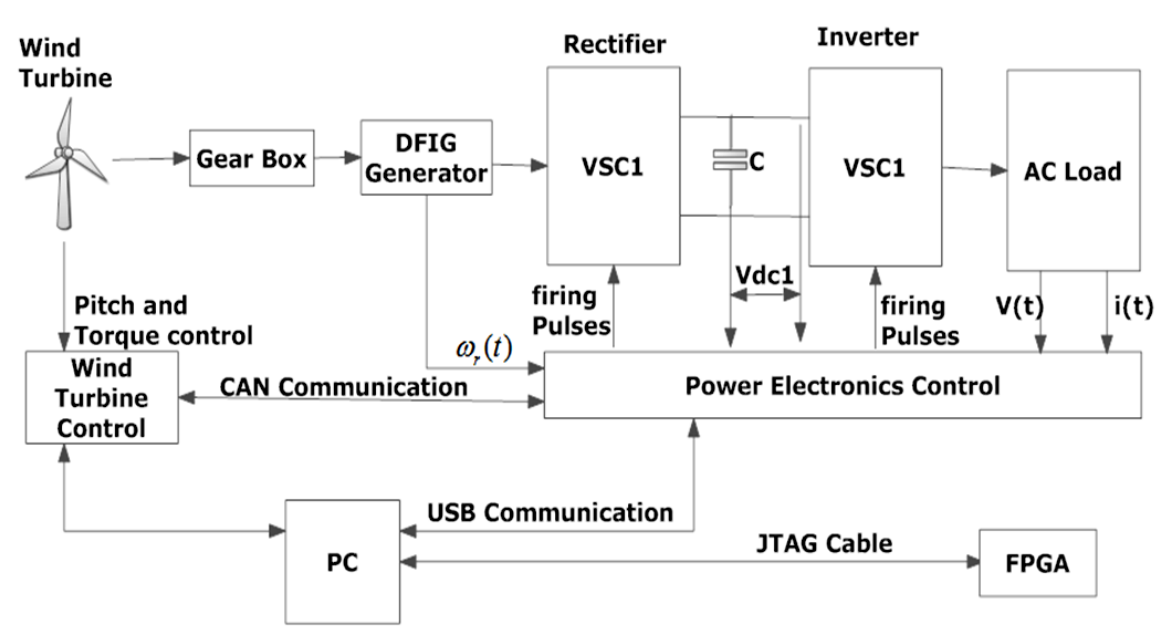

Figure 1. Block diagram of WECSs.

\section{Modeling of WECS}

\subsection{Wind turbine modeling}

The aerodynamic power of the wind turbine is modeled with

$$
\begin{gathered}
P_{m}=0.5 \rho A C_{P}(\lambda, \beta) V_{w}^{3} \\
C_{P}(\lambda, \beta)=0.73\left[\frac{151}{\lambda}-0.58 \beta-0.002 \beta^{2.14}-13.2\right] e^{\left(-\frac{18.4}{\lambda_{i}}\right)} \\
\lambda_{i}=\left(\frac{1}{\lambda-0.02 \beta}-\frac{0.03}{\beta^{3}+1}\right)^{-1} .
\end{gathered}
$$

Tip speed ratio $\lambda$ and pitch angle $\beta$ are given by

$$
\lambda=\frac{\omega_{r} R_{r}}{V_{w}}, \quad \beta=\frac{\omega_{r}^{3}}{P_{M P P}}
$$

where $C_{P}$ is the power coefficient, $\omega_{r}$ is turbine rotational speed, $\rho$ is air density in $\mathrm{gram} / \mathrm{m}^{3}, A$ is the cross sectional area of turbine, $V_{w}$ is wind velocity and $R_{r}$ is the radius of turbine shaft.

\subsection{Drive train subsystem of wind turbine}

The drive train model is given by

$$
T_{w}-T_{e m}=J \frac{d \omega_{m}}{d t}+B \omega_{m}
$$


where $J$ is the total inertia, $T_{e m}$ is the electromagnetic torque of generator, $T_{w}$ is the input mechanical torque extracted from the aerodynamic power and $B$ is the effective friction coefficient. $T_{e m}$ can be calculated as follows

$$
\begin{gathered}
T_{e m}=\frac{P_{e m}}{\omega_{m}} \\
\dot{\omega}_{e}=\frac{P_{m}}{J}\left(\frac{T_{w}}{N}+T_{e m}\right) \\
\omega_{e}=P_{m} \omega_{g}=P_{m} N \omega_{m}
\end{gathered}
$$

where $P_{e m}$ is the electromagnetic power of the generator, $\omega_{m}$ is mechanical rotor speed, $\omega_{e}$ is the electrical rotor speed, $P$ is the number of pole pairs and $N$ is the gear ratio.

\subsection{Voltage-current relationships applied in dq reference frame using generator convention}

The three phase abc quantities for DFIG are transformed into dq transformation using Parks transformation, since the representation of state space equations are simpler in dq transformation.

$$
\left[\begin{array}{l}
v_{d s}=-R_{s} i_{d s}+\omega_{s}\left(\left(L_{s}+L_{m}\right) i_{q s}+L_{m} i_{q r}\right) \\
v_{q s}=-R_{s} i_{q s}-\omega_{s}\left(\left(L_{s}+L_{m}\right) i_{d s}+L_{m} i_{d r}\right) \\
v_{d r}=-R_{r} i_{d r}+s \omega_{s}\left(\left(L_{r}+L_{m}\right) i_{q r}+L_{m} i_{q s}\right) \\
v_{q r}=-R_{r} i_{q r}-s \omega_{s}\left(\left(L_{r}+L_{m}\right) i_{d r}+L_{m} i_{d s}\right)
\end{array}\right]
$$

where $s=$ slip, indices $s$ and $r$ respectively denote for stator and rotor.

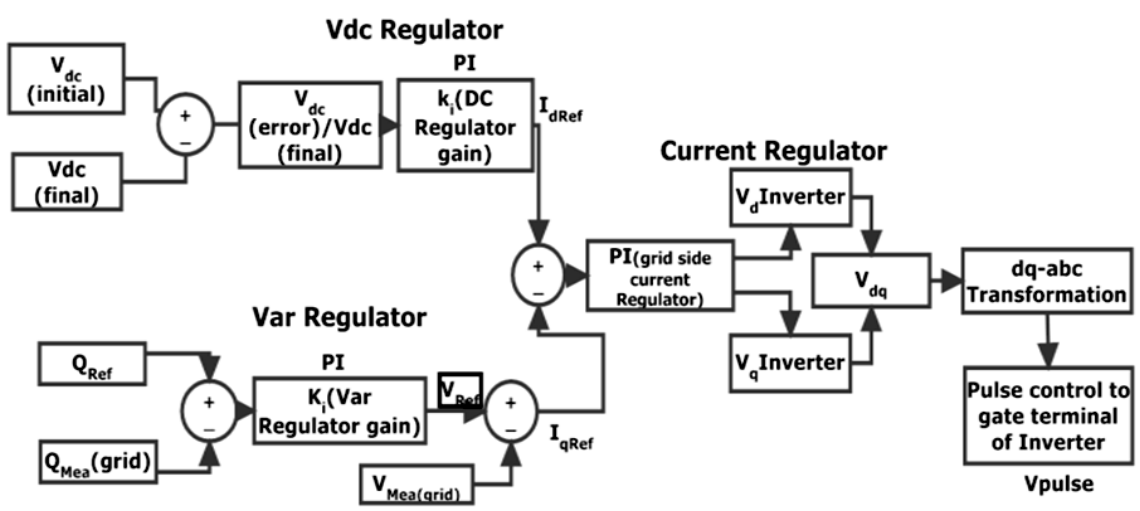

Figure 2. Grid side converter control system. 
The firing pulses for the grid converter are explained in Fig. 2. The firing pulses are derived from the regulated DC voltage and the reactive power from the grid. The three phase quantities are converted to dq reference values for Proportional Integral (PI) control and later converted again from dq to abc for firing the converter on grid side.

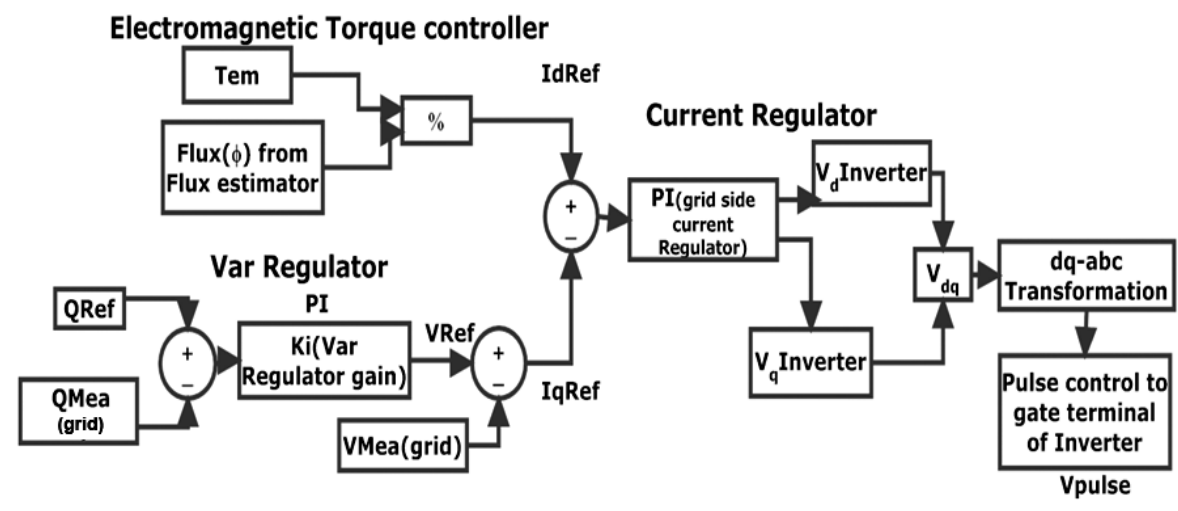

Figure 3. Rotor side converter controller.

The firing pulses for the rotor side converter are explained in Fig. 3. The firing pulses have been derived from the electromagnetic torque, stator flux estimation and the reactive power from the grid.

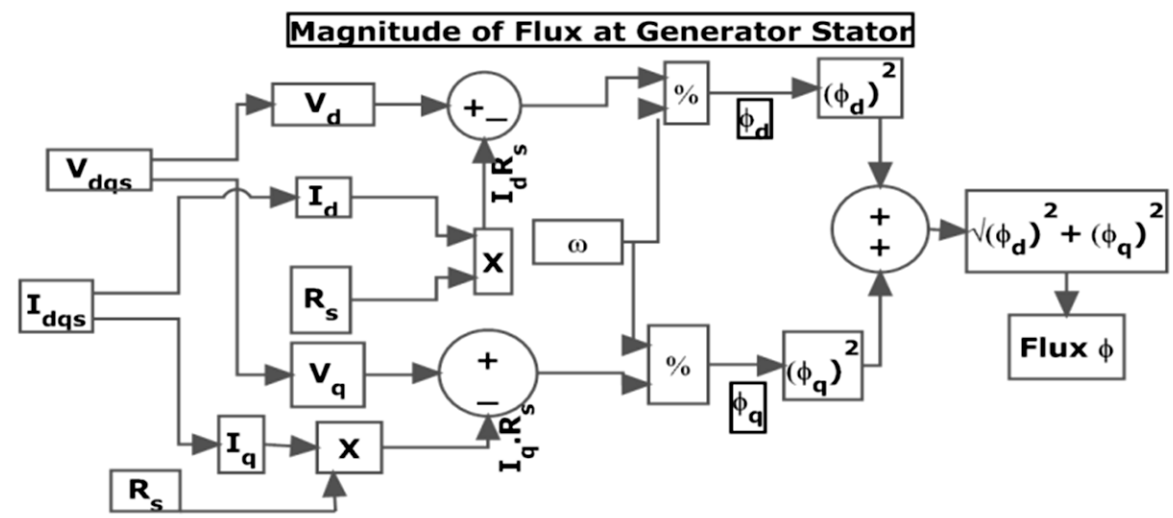

Figure 4. Stator flux estimator. 
Fig. 4 explains the stator flux estimation from stator $V_{d q s}$ and $I_{d q s}$ as per the equations (10)-(13):

$$
\begin{gathered}
{\left[\begin{array}{c}
v_{d s} \\
v_{q s} \\
v_{d r} \\
v_{q r}
\end{array}\right]=\left[R^{*}\right]\left[\begin{array}{c}
i_{d s} \\
i_{q s} \\
i_{d r} \\
i_{q r}
\end{array}\right]+\frac{d}{d t}\left[\begin{array}{c}
\psi_{d s} \\
\psi_{q s} \\
\psi_{d r} \\
\psi_{q r}
\end{array}\right]+\left[\Omega^{*}\right] \frac{d}{d t}\left[\begin{array}{l}
\psi_{d s} \\
\psi_{q s} \\
\psi_{d r} \\
\psi_{q r}
\end{array}\right]} \\
R^{*}=\left[\begin{array}{cccc}
R_{s} & 0 & 0 & 0 \\
0 & R_{s} & 0 & 0 \\
0 & 0 & R_{r} & 0 \\
0 & 0 & 0 & R_{r}
\end{array}\right] \\
\Omega^{*}=\left[\begin{array}{cccc}
0 & -\omega_{o} & 0 & 0 \\
\omega_{o} & 0 & 0 & 0 \\
0 & 0 & 0 & -\Delta \omega \\
0 & 0 & \Delta \omega & 0
\end{array}\right] \\
{\left[\begin{array}{c}
\psi_{d s} \\
\psi_{q s} \\
\psi_{d r} \\
\psi_{q r}
\end{array}\right]=\left[\begin{array}{cccc}
L_{s} & 0 & L_{m} & 0 \\
0 & L_{s} & 0 & L_{m} \\
L_{m} & 0 & L_{r} & 0 \\
0 & L_{m} & 0 & L_{r}
\end{array}\right]\left[\begin{array}{c}
i_{d s} \\
i_{q s} \\
i_{d r} \\
i_{q r}
\end{array}\right] .}
\end{gathered}
$$

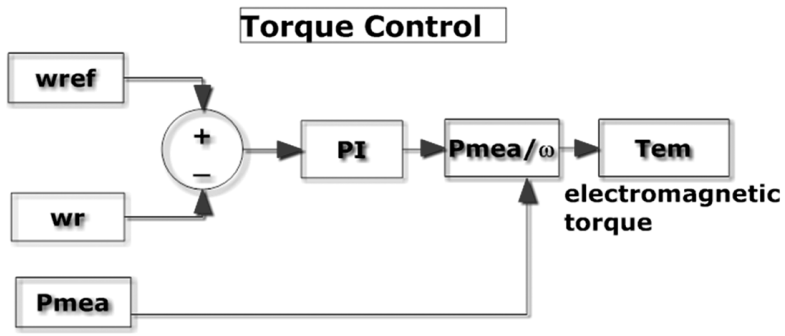

Figure 5. Torque control on rotor side converter.

The electromagnetic torque $T_{e m}$ is obtained from the rotor speed of generator and the measured value of power. If the speed is less than the nominal speed, then reference is calculated and the torque control comes into picture as shown in Fig. 5. If the speed is above the nominal speed then the pitch control is activated as explained in Fig. 6. 


\section{Pitch Control}

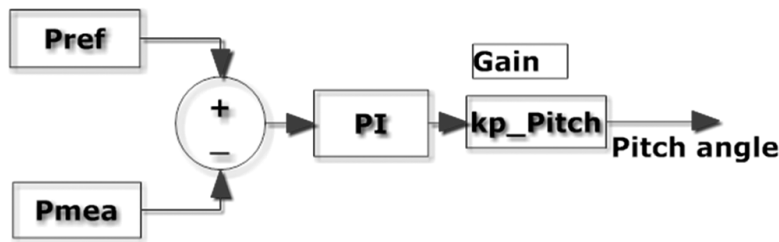

Figure 6. Pitch control on rotor side converter.

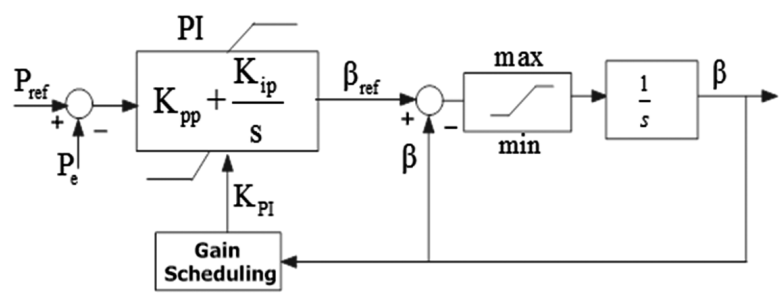

Figure 7. Gain scheduling for pitch control.

The scheduling constant $K_{P I}$ which has been used in Fig. 7 is given as follows

$$
K_{P I}=\left\{\begin{array}{ccc}
1 & \text { for } & -3^{\circ}<\beta \leqslant 0^{\circ} \\
\frac{\beta}{15}+1 & \text { for } & 0^{\circ}<\beta \leqslant 30^{\circ} \\
3 & \text { for } & \beta>30^{\circ}
\end{array}\right\} .
$$

Selection of $K_{p p}, K_{i p}$, and $K_{P I}$ is done by trial and error method, based on minimizing deviations from the set point without excessive control action and without causing any instability.

\subsection{FPGA design flow}

System Generator works within the SIMULINK model-based design methodology. An executable spec is created using the standard SIMULINK block sets as shown in Fig. 8. Once the functionality and basic dataflow issues have been defined, system generator can be used to specify the hardware implementation details for the Xilinx devices. System generator uses the Xilinx block set for SIMULINK and will automatically invoke Xilinx Core Generator to generate highly optimized netlists for building blocks. System generator can execute all the downstream implementation tools to produce a bit stream for programming the FPGA. An optional test bench can be created using test vectors 


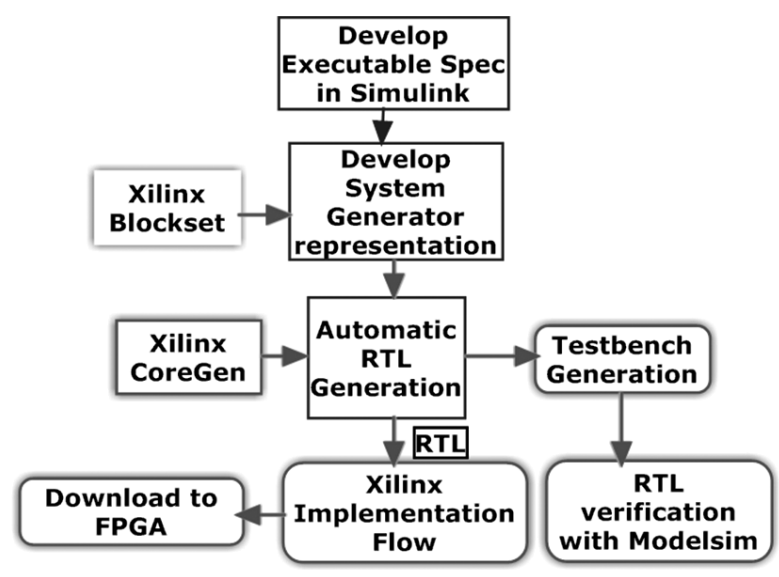

Figure 8. Design Flow in FPGA implementation.

extracted from the SIMULINK environment for use with ModelSim or the Xilinx ISE Simulator.

\subsection{JTAG co-simulation}

The symbol for "JTAG Co-Simulation" in SIMULINK is given in Fig. 9.

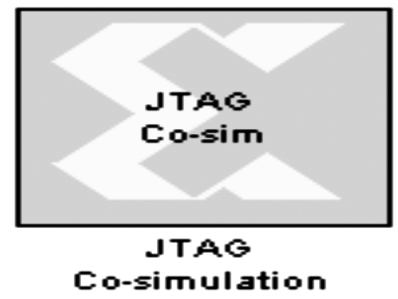

Figure 9. JTAG Co-Simulation.

JTAG stands for Joint Test Action Group. JTAG boundary scan started as a method of testing ICs and their interconnections using a shift register built into the chip so that inputs could be shifted-in and the resulting outputs could be shifted-out using only four I/O pins (clock, input data, output data, and state machine mode control). This eliminated the need for complex, expensive, bed-of-nails cards for low-speed probing of IC I/O pins. JTAG is used for debugging software, hardware co-simulation. When a model is implemented for JTAG hardware co-simulation, a new library is created that contains a custom JTAG co-simulation block with ports that match the gateway names from the original model. The co-simulation block interacts with the FPGA hardware platform 
during a SIMULINK simulation. Simulation data that written to the input ports of the block are passed to the hardware by the JTAG block.

System generator provides "Hardware Co-Simulation", making it possible to incorporate a design running in an FPGA directly into a SIMULINK simulation. Hardware Co-Simulation compilation targets automatically create a bit stream and associate it to a block. When the design is simulated in SIMULINK, results for the compiled portion are calculated in hardware. This allows the compiled portion to be tested in actual hardware and can speed up simulation dramatically.

\section{Controller design for pitch and torque control}

In this section, torque and pitch controllers have been developed using SMC. Initially an observer is developed to estimate the aerodynamic torque and rotor acceleration. After that torque controller is designed to maximize the generating power and pitch controller is designed to maintain the rated rotor speed so that the generated power is regulated.

The wind power system is represented by state space equations as

$$
\begin{gathered}
i_{d}=-\frac{R_{s}}{L} i_{d}+\omega_{e} i_{q}+\frac{1}{L} V_{d} \\
\dot{i}_{q}=-\frac{R_{s}}{L} i_{q}-\omega_{e} i_{d}-\frac{\omega_{e} \phi}{L}+\frac{1}{L} V_{q} \\
\dot{\omega}_{e}=\frac{P_{m}}{J}\left(\frac{T_{w}}{N}+T_{e m}\right)
\end{gathered}
$$

where the dq axis voltages are control inputs and $i_{d}, i_{q}$ and $\omega_{e}$ are state variables.

The wind power system is operated within the specific range of wind speed. If the wind speed is out of range, then the wind turbine will be off and does not generate the power. Similarly the pitch angle should be within the prescribed limits as explained above in gain scheduling pitch control mechanism, beyond which the wind power system will be off and does not generate the power.

\subsection{Observer design}

For estimating the aerodynamic torque and rotor speed in torque and pitch control, sliding mode observer is designed based on super twisting algorithm [9].

$$
\begin{gathered}
\dot{\hat{\omega}}_{e}=\frac{P}{J} T_{e m}+u_{1}-\mu|e|^{\frac{1}{2}} \operatorname{sgn}(e) \\
e=\hat{\omega}_{e}-\omega_{e} .
\end{gathered}
$$

According to the super twisting algorithm, $e$ and $\dot{e}$ converge to zero in finite time to avoid the chattering phenomenon and thus $T_{w}, \omega_{e}$ can be estimated and $\mu$ is the positive constant. 


\subsection{Torque controller design}

Torque controller should be designed to maximize the generating power below the rated speed. To achieve this, $C_{P}$ should maintain the maximum value $C_{P}\left(\lambda_{\text {opt }}, \beta^{*}\right)$. Thus the pitch angle $\beta$ is set to $\beta^{*}$. For obtaining the maximum value of $C_{P}$, the aerodynamic torque is expressed as

$$
\begin{gathered}
T_{\text {wopt }}=\frac{\rho \pi r^{5} C_{P}\left(\lambda_{\text {opt }}, \beta^{*}\right)}{2 N^{2} P^{2} \lambda^{3}{ }_{\text {opt }}} \omega_{\text {eopt }}^{2}=K_{\text {opt }} \omega_{\text {eopt }}^{2} \\
K_{\text {opt }}=\frac{\rho \pi r^{5} C_{P}\left(\lambda_{\text {opt }}, \beta^{*}\right)}{2 N^{2} P^{2} \lambda_{\text {opt }}^{3}}
\end{gathered}
$$

and

$$
\omega_{\text {eopt }}=\frac{N P v \lambda_{\text {opt }}}{r}
$$

where $K_{\text {opt }}$ is the constant value and $\omega_{\text {eopt }}$ is the rotor speed when the wind turbine generates the maximum power at a given wind speed. $\omega_{\text {eopt }}$ is a function of wind speed $v$. For tracking the MPPT, the generator torque $T_{e}$ should track the optimal aerodynamic torque $T_{\text {wopt }}$ considering the gear ratio. Sliding surface for the torque controller is designed as

$$
\begin{gathered}
S_{d}=\zeta\left(i_{\text {dref }}-i_{d}\right) \\
S_{q}=K_{o p t} \omega_{e}^{2}+\frac{3}{2} N P \phi i_{q}
\end{gathered}
$$

where $\zeta<0, i_{d r e f}$ is set to zero and $S_{q}$ is to maximize the generating power.

\subsection{Pitch controller design}

The generating power is given by

$$
P_{e}=T_{e} \omega_{g}=T_{e} \frac{\omega_{e}}{P}=-\frac{K_{o p t} \omega_{e}^{3}}{N P} .
$$

From the above equation, the generating power is determined by the rotor speed $\omega_{e}$. When the wind speed is above the rated speed, the power should be regulated and this is done by pitch controller. For regulating the power, the pitch angle $\beta$ should be regulated so that $\omega_{e}$ approaches the rated value $\omega_{e}^{*}$ which means that $P_{e}$ converges to its rated value

$$
P_{e}^{*}=-\frac{K_{o p t}\left(\omega_{e}^{*}\right)^{3}}{N P} .
$$

The pitch controller is designed in such a way that it operates only in the range of $\omega_{e}>$ $\omega_{e}^{*}$. The pitch angle dynamics is modelled as a first order system which is given by

$$
\frac{d \beta}{d t}=\frac{1}{T_{\beta}}\left(u_{\beta}-\beta\right)
$$


Table 3. Parameters of WECSs

\begin{tabular}{|c|c|c|}
\hline Controller parameters & Notation & Value \\
\hline Rotor radius & $R$ & $35 \mathrm{~m}$ \\
\hline Air density & $\rho$ & $1.5 \mathrm{~kg} / \mathrm{m}^{3}$ \\
\hline Resistance & $R_{s}$ & $0.1 \Omega$ \\
\hline Inductance & $L$ & $0.005 \mathrm{H}$ \\
\hline Field flux & $\phi$ & $15.68 \mathrm{Vs} / \mathrm{rad}$ \\
\hline Equivalent inertia & $J$ & $6000 \mathrm{kgm}$ \\
\hline Number of pole pairs & $P$ & 2 \\
\hline Gear ratio & $N$ & 67 \\
\hline Time constant of pitch actuator & $T_{\beta}$ & $0.1 \mathrm{~s}$ \\
\hline Pitch rate limit & $R_{\beta}$ & $8 \mathrm{deg} / \mathrm{s}$ \\
\hline
\end{tabular}

\begin{tabular}{|c|c|c|}
\hline Observer parameters & Notation & Value \\
\hline Constant & $M$ & 12000 \\
\hline
\end{tabular}

\begin{tabular}{|c|c|c|}
\hline Sliding torque controller & Notation & Value \\
\hline Constant & $\zeta$ & -1 \\
\hline
\end{tabular}

\begin{tabular}{|c|c|c|}
\hline Sliding pitch controller & Notation & Value \\
\hline Constant & $\omega_{e}$ & $1.025 \mathrm{rad} / \mathrm{s}$ in $\mathrm{p} . \mathrm{u}$. \\
\hline
\end{tabular}

where $u_{\beta}$ is the control to be designed.

The sliding surface $S_{\beta}$ is selected by using the Lyapunov function

$$
\dot{V} \leqslant\left(\sigma-K_{\beta}\right)\left|S_{\beta}\right|
$$

Because $\dot{V}<0$ except at $S_{\beta}=0$, the system trajectory reaches the sliding surface $S_{\beta}=0$ in finite time. As a result, the rotor speed asymptotically converges to $\omega_{e}^{*}$ and the rotor acceleration asymptotically converges to zero. 
Table 4. Total harmonic distortion

\begin{tabular}{|c|c|}
\hline Parameter & THD \\
\hline$V_{d c}$ & 0.5413 \\
\hline$I$ & 0.0967 \\
\hline$T_{e m}$ & 0.4383 \\
\hline$T_{m}$ & 0.9603 \\
\hline$\omega_{g}$ & 1.0127 \\
\hline$\beta$ & 0.7394 \\
\hline
\end{tabular}

\section{Results and discussion}

The WECS was simulated using MATLAB/ SIMULINK and also implemented in FPGA. The sliding mode controller was designed for a wind turbine with a $3 \mathrm{~kW}$ DFIG. The rated wind speed $\mathrm{w}$ taken as $12 \mathrm{~m} / \mathrm{s}$. The mean wind speed increases from $11 \mathrm{~m} / \mathrm{s}$ to $14 \mathrm{~m} / \mathrm{s}$ at $t=2.5 \mathrm{~s}$ and then it keeps over the rated value with the wind turbulence and in this simulation study the turbulence intensity is $8 \%$. The pitch rate is limited to $8 \mathrm{deg} / \mathrm{s}$. The simulation result can be divided into two parts. In the region $\omega_{g} \leqslant \omega_{g}^{*}$, the torque controller tries to maximize the generating power, while in the region $\omega_{g} \geqslant \omega_{g}^{*}$, the torque control and pitch control operate in harmony to regulate the inlet power. From the simulation results, it becomes clear that the proposed controller can successfully regulate the inlet power.

For obtaining the MPPT, two controllers has been proposed using SMC and these compared with traditional methods like Hill Climbing, perturb and observe. It has been verified from the results that SMC has given better results. Various parameters have been plotted i.e. pitch angle, active power, reactive power, turbine speed, DC voltage versus time, hysteresis plot and total harmonic distortion (THD) for various parameters. In Fig. 10, time taken for varying the pitch angle is less compared to $\mathrm{HC}$ and $\mathrm{P} \& \mathrm{O}$, to obtain the normal speed for better power regulation. In Fig. 11 and 12, the active and reactive power variations have been observed. Active power has attained maximum value using SMC when compared to $\mathrm{HC}$ and $\mathrm{P} \& \mathrm{O}$. At the same time, reactive power has come to minimum value at $t=2.3 \mathrm{~s}$ but for $\mathrm{HC}$ and $\mathrm{P} \& \mathrm{O}$, reactive power $Q$ has been increased above SMC. In Fig. 13, the turbine speed has been better regulated and in Fig. 14, the DC voltage in p.u has better value compared to $\mathrm{HC}$ and P\&O. In Fig. 15, the hysteresis curve has been plotted which gives the iron loss for DFIG generator. Fig. 16-21 shows the total harmonic distortion (THD) for various parameters listed in Table 2. 


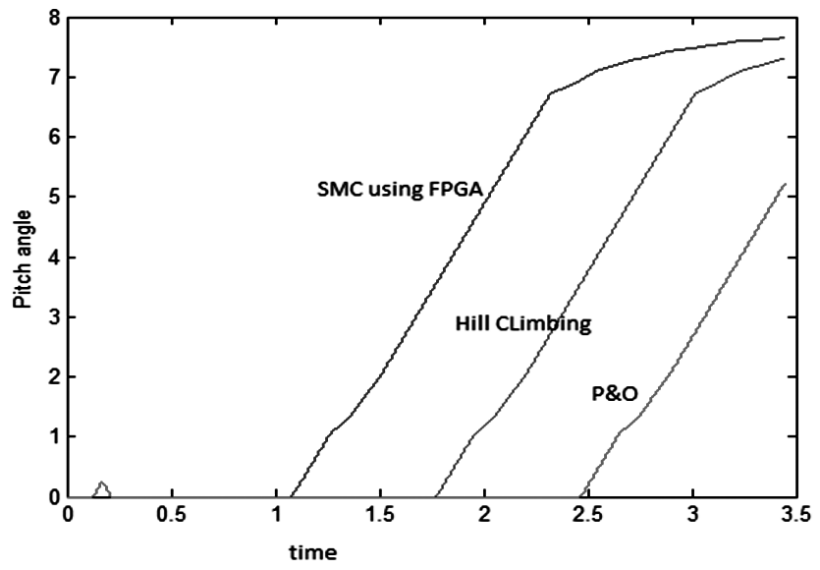

Figure 10. Pitch angle $\beta$ (deg) versus time (sec).

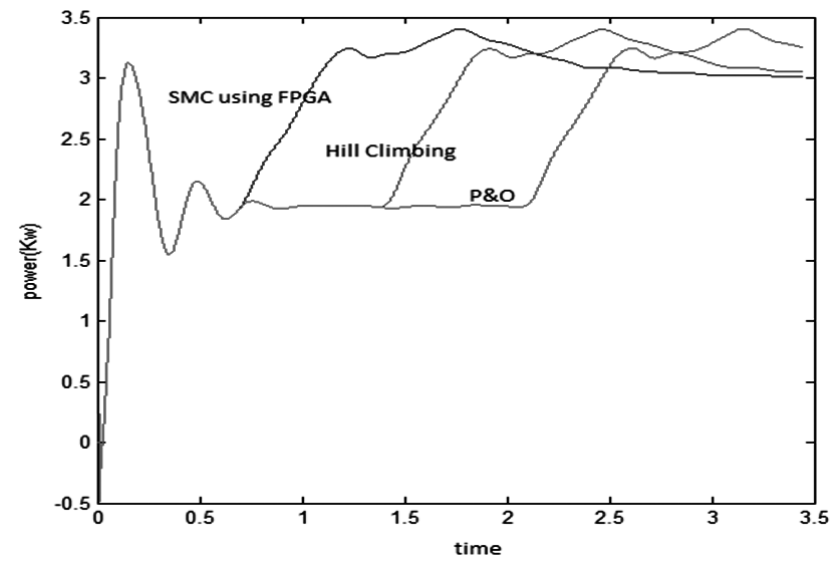

Figure 11. Active power $P(\mathrm{Kw})$ versus time (sec).

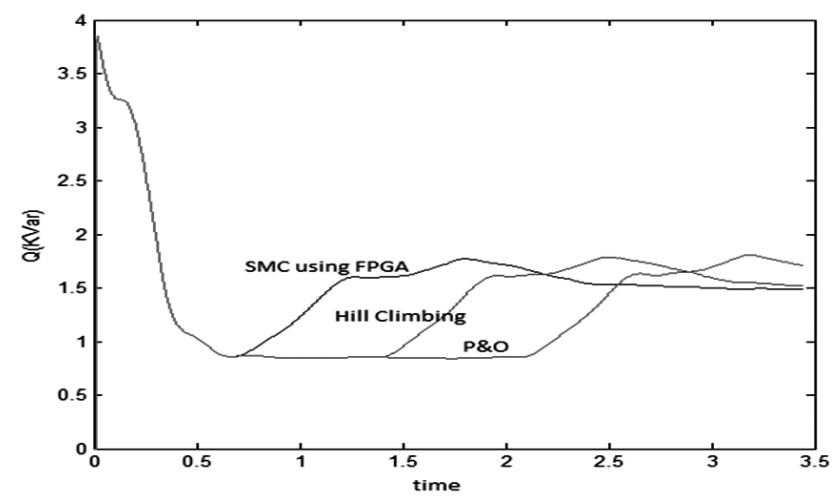

Figure 12. Reactive power $Q$ (KVar) versus time (sec). 


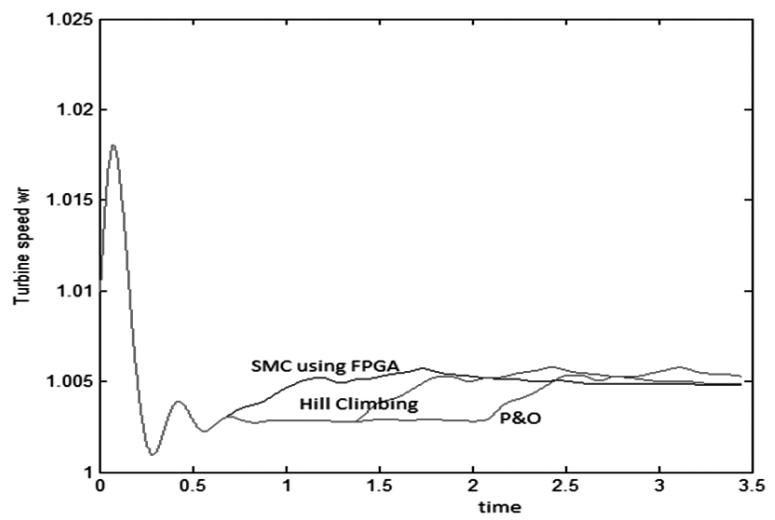

Figure 13. Turbine speed $\omega$ versus time (sec).

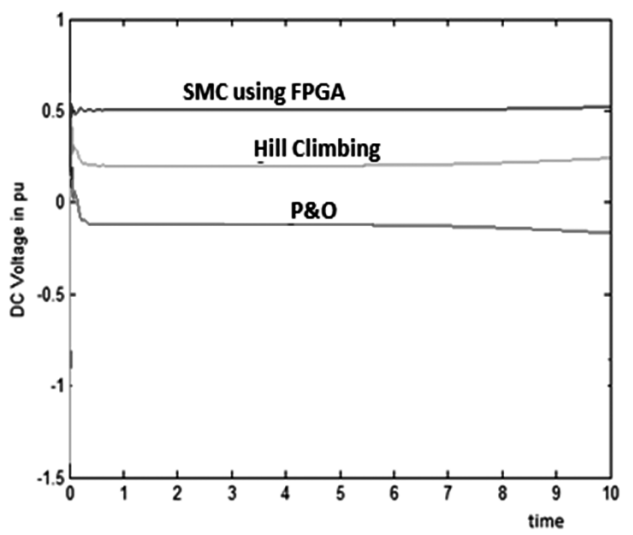

Figure 14. DC voltage $V_{d c}$ (volts) versus time (sec).

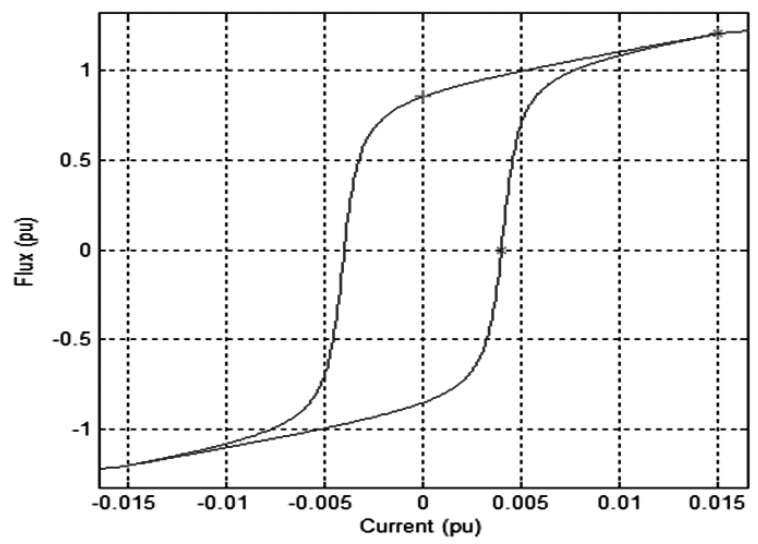

Figure 15. Hysteresis curve for iron loss. 


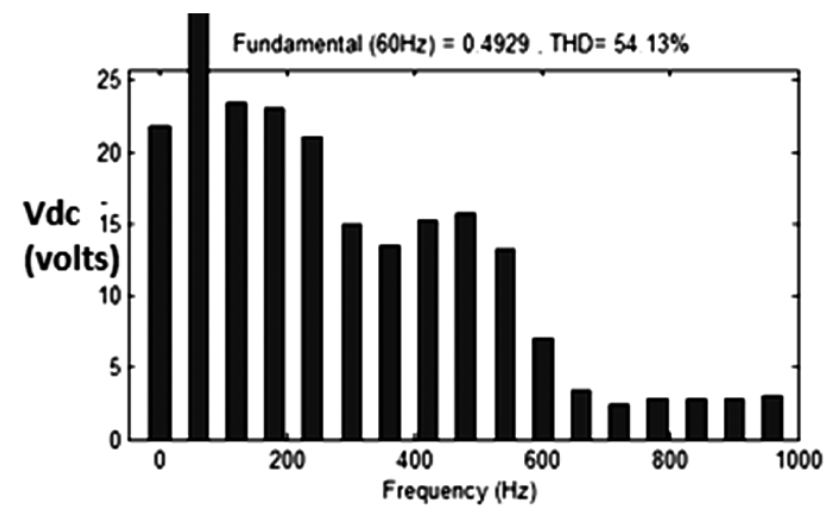

Figure 16. THD for DC voltage versus frequency.

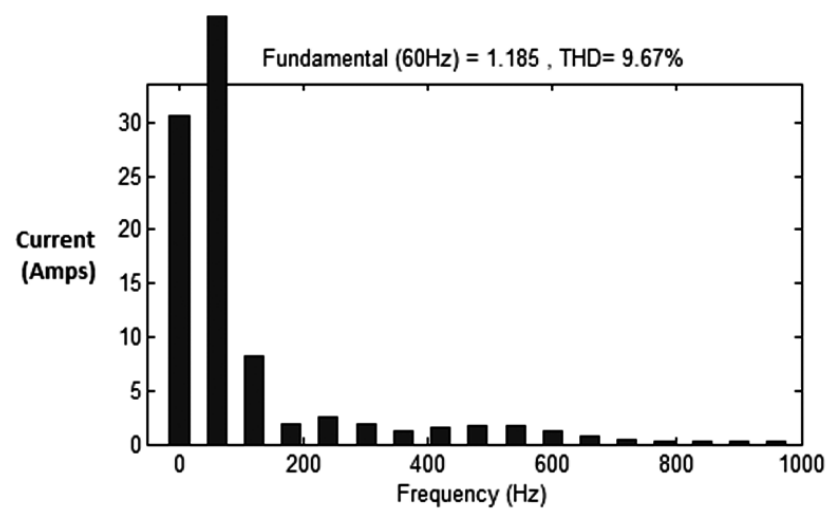

Figure 17. THD for current versus frequency.

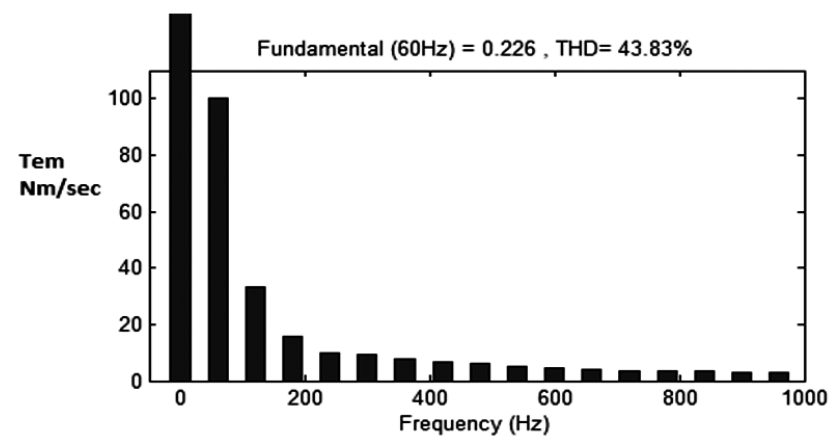

Figure 18. THD for electromagnetic torque $T_{e m}$ versus frequency. 


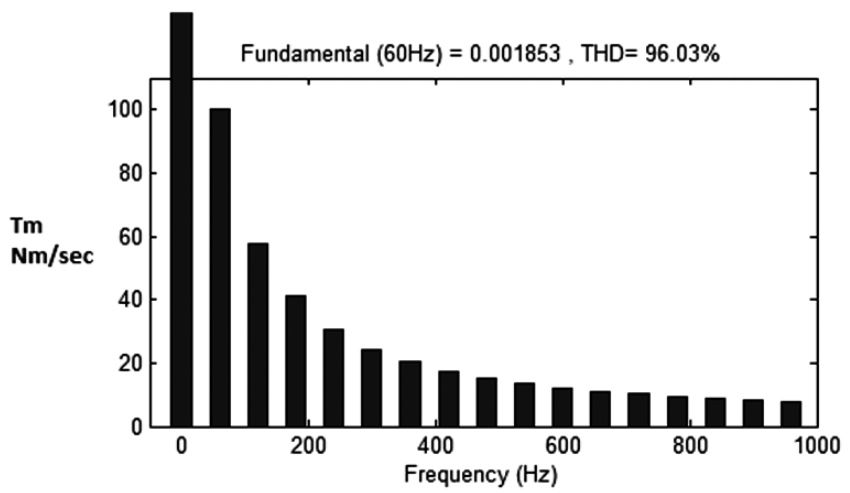

Figure 19. THD for mechanical torque $T_{m}$ versus frequency.

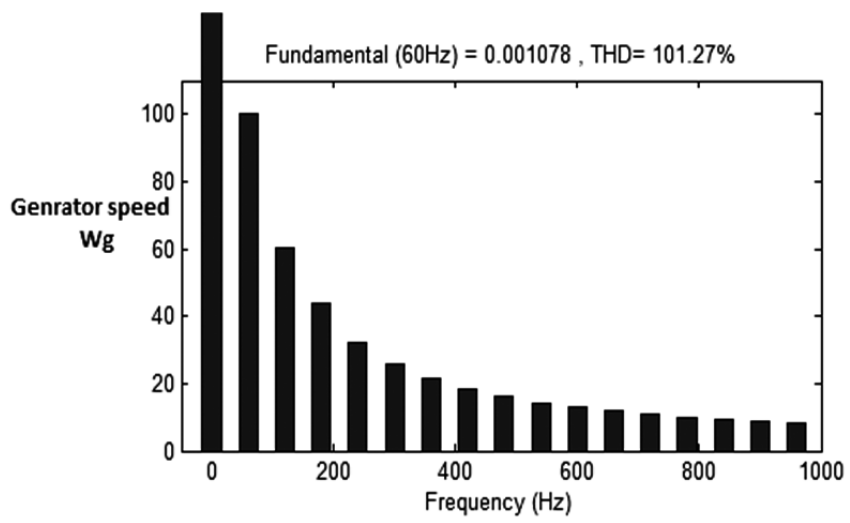

Figure 20. THD for generator speed versus frequency.

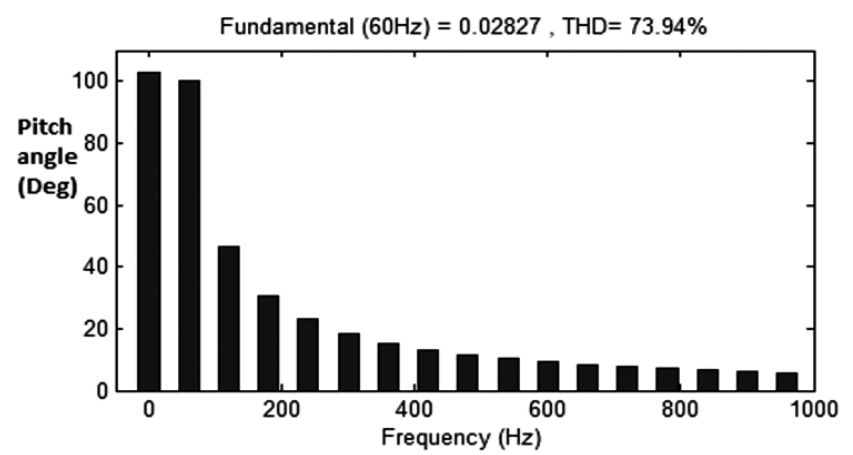

Figure 21. THD for pitch angle $\beta$ versus frequency. 


\section{Conclusions}

In this paper, Sliding mode control scheme for the wind turbine system based on a DFIG. An observer is constructed to estimate the turbine torque and the rotor acceleration, and with which a torque controller and a pitch controller are designed employing the sling mode control scheme. In order to verify the proposed control strategy, the simulations in MATLAB/SIMULINK as well as implementation in FPGA has been performed. Simulation results and implementation in FPGA show that control objectives are well achieved in spite of the wind turbulence.

Sliding Mode control has been applied for torque and pitch control of WECS. SMC has been simulated in MATLAB/SIMULINK and practically implemented in FPGA through JTAG cable. Later SMC has been compared with the HC and P\&O. The results obtained in SMC are better than the HC and P\&O. The THD has also been reduced to a considerable extent. FPGA has made the complex manipulations in SMC faster, reliable. SMC technique provided robustness to the Pitch and Torque control in WECSs

\section{References}

[1] L. Soder, L. Hofmann, A. Orths, H. Holttinen, Y. Wan and A. Tuohy: Experience from wind integration in some high penetration areas. IEEE Trans. Energy Convers., 22(1), (2007), 4-12.

[2] F. Lescher, J. Y. ZHAO and P. BORnE: Robust gain scheduling controller for pitch regulated variable speed wind turbine. Stud. Inform. Control, 14(12), (2005), 299-315.

[3] F. BiAnChi, R. MAntz and C. Christiansen: Gain scheduling control of variable speed wind energy conversion systems using quasi-PV models. Control Eng. Practice, 13(2), (2005), 247-255.

[4] D. LEITH and W. LeITHEAD: Appropriate realisation of gain-scheduled controllers with application to wind turbine regulation. Int. J. Control, 65(2), (2005, 223-248.

[5] K. Stol, B. Rigney and M. BALAS: Disturbance accommodating control of a variable-speed turbine using a symbolic dynamics structural model. Proc. 2000 ASME Wind Energy Symp., Reno, Nevada, (2000), 84-90.

[6] D.H. Battista, R.J. Mantz and C.F. Christiansen: Dynamical sliding mode power control of wind driven induction generators. IEEE Trans. on Energy Conversion, 5(4), (2000), 451-457.

[7] E.B. Muhando, T. Senjyu, A. Uehara, T. Funabashi and C-H. Kim: Gainscheduled $H_{\infty}$ control for WECS via LMI techniques and parametrically dependent 
feedback. Part II: Controller design and implementation. IEEE Trans. on Industrial Electronics, 58(1), (2011), 57-65.

[8] X.-Y. ZhANG, J. WU and J.-M. YANG: $H_{\infty}$ robust control of constant power output for the wind energy conversion system above rated wind. IET Control Theory and Application, 25(2), (2008), 321-324.

[9] B. Beltran, T. Ahmed-Ali and M.E.H. Benbouzid: High-order sliding mode control of variable-speed wind turbines. IEEE Trans. on Industrial Electronics, 56(9), (2009), 3314-3321. 